WORKING PAPER · NO. 2020-04

\title{
Central Bank Digital Currency: Central Banking For All?
}

Jesús Fernández-Villaverde, Daniel Sanches, Linda Schilling, and Harald Uhlig JANUARY 2020

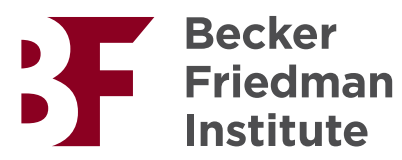




\title{
Central Bank Digital Currency: Central Banking For All?
}

\author{
Jesús Fernández-Villaverde - University of Pennsylvania, NBER and CEPR \\ Daniel Sanches - Federal Reserve Bank of Philadelphia \\ Linda Schilling - Ecole Polytechnique, CREST \& CEPR \\ Harald Uhlig - University of Chicago, CEPR, NBER*
}

January 15,2020

\begin{abstract}
The introduction of a central bank digital currency (CBDC) allows the central bank to engage in large-scale intermediation by competing with private financial intermediaries for deposits. Yet, since a central bank is not an investment expert, it cannot invest in long-term projects itself, but relies on investment banks to do so. We derive an equivalence result that shows that absent a banking panic, the set of allocations achieved with private financial intermediation will also be achieved with a CBDC. During a panic, however, we show that the rigidity of the central bank's contract with the investment banks has the capacity to deter runs. Thus, the central bank is more stable than the commercial banking sector. Depositors internalize this feature ex-ante, and the central bank arises as a deposit monopolist, attracting all deposits away from the commercial banking sector. This monopoly might endangered maturity transformation.

Keywords: central bank digital currency, central banking, intermediation, maturity transformation, bank runs, lender of last resort.

JEL classifications: E58, G21

*jesusfv@econ.upenn.edu, Daniel.Sanches@phil.frb.org, lin.schilling@gmail.com, and huhlig@uchicago.edu. The contribution of Linda Schilling has been prepared under the Lamfalussy fellowship program sponsored by the ECB. The views expressed in this paper are those of the authors and do not necessarily reflect the views of the ECB, the Federal Reserve Bank of Philadelphia, or the Federal Reserve System. The project was partially written during a research stay of Linda Schilling at the Simons Institute at UC Berkeley. The support and hospitality of Simons is gratefully acknowledged. We thank Larry Christiano, Todd Keister, Chris Sims, and participants at different seminars for useful feedback.
\end{abstract}




\section{Introduction}

Recent advances in cryptographic and distributed ledger techniques (von zur Gathen, 2015; Narayanan et al., 2016) have opened the door to the widespread use of digital currencies. While the lead in the introduction of these currencies came from private initiatives such as Bitcoin, Ethereum, and Libra, researchers and policymakers have explored the possibility that central banks can also issue their own digital currencies, aptly called a central bank digital currency (CBDC). ${ }^{1}$

The introduction of a CBDC can represent an important innovation in money and banking history. Besides its potential role in eliminating physical cash, a CBDC will allow the central bank to engage in large-scale intermediation by competing with private financial intermediaries for deposits (and, likely, engaging in some form of lending of those deposits). In other words, a CBDC amounts to giving consumers the possibility of holding a bank account with the central bank directly.

Defenders of a CBDC have been rather explicit about this implication. For instance, Barrdear and Kumhof (2016, p. 7) state: "By CBDC, we refer to a central bank granting universal, electronic, 24x7, national-currency-denominated and interest-bearing access to its balance sheet." In this paper, we will use these authors' definition as the working concept of a CBDC. ${ }^{2}$

Similarly, Bordo and Levin (2017) propose that either a "an account-based CBDC could be implemented via accounts held directly at the central bank" [p. 7], or "CBDC could be provided to the public via specially designated accounts at supervised commercial banks, which would hold the corresponding amount of funds in segregated reserve accounts at the central bank" [p. 8], and which is now often referred to as a synthetic CBDC. In this formulation, the differences between a CBDC held directly at the central bank or at a commercial

\footnotetext{
${ }^{1}$ See, as examples and without trying to be exhaustive, Adrian and Mancini-Griffoli (2019), Agur et al. (2019), Barontini and Holden (2019), Berentsen and Schar (2018), Brunnermeier et al. (2019), Barrdear and Kumhof (2016), Bordo and Levin (2017), Danezis and Meiklejohn (2015), Dyson and Hodgson (2016), Ketterer and Andrade (2016), Mancini-Griffoli et al. (2018), Rogoff (2014), and Wadsworth (2018). In terms of central banks, the BIS has circulated numerous position papers on CBDCs, the Sveriges Riksbank has studied this issue in detail with its E-krona project, and the Bank of Japan has reported on the legal issues regarding CBDCs. See https://www.bis.org/cpmi/publ/d174.pdf and https://www.riksbank.se/en-gb/ payments--cash/e-krona/ and http://www.boj.or.jp/en/research/wps_rev/lab/lab19e03.htm/.

${ }^{2}$ Notice, therefore, that the sense in which most economists have defined a CBDC as an account-based currency goes well beyond a basic notion of central bank-issued electronic money (which may or may not fully replace physical cash). To focus our investigation, we will avoid the discussion of the relative merits of other forms of central bank-issued electronic money, such as a token-based central bank cryptocurrency or traditional electronic reserves. Conversely, one could consider situations where the central bank opens its account facilities to all citizens, even in the absence of a CBDC. As we will see in Section 2, this opening has occurred often in history, and it was defended in the 1980s by Tobin (1987, p. 172) as "deposited currency." Nearly all of the analysis in our paper carries over to a "deposited currency" environment.
} 
bank with segregated reserves are mostly inconsequential for our analysis, for they have the same implications for financial intermediation.

We could be, thus, at a juncture where changes in technology -namely, the introduction of digital currencies- may justify a fundamental shift in the architecture of a financial system, a central bank "open to all." As argued by Friedman and Schwartz (1986) in a classic paper, external forces -in this case, technological innovations- might shape how we think about the role of government in setting up monetary and financial institutions and make us opt for alternative arrangements.

These considerations are already relevant to monetary policy. In June 2018, Swiss voters turned down the sovereign-money (Vollgeld) initiative that would have given the central bank a monopoly on issuing demand deposits, an idea motivated in part by the possibility of a Swiss CBDC. Despite the Vollgeld initiative being soundly defeated at the ballot box, similar designs are bound to be widely discussed during the coming years.

What effects will the introduction of a CBDC and the opening of central bank facilities have on financial intermediation? Will a CBDC impair the role of the financial system in allocating funds to productive projects? Or can we reorganize the financial system in such a way that a CBDC will still allow the right flow of funds between savers and investors? Will a CBDC make bank runs disappear and stabilize the financial system?

In this paper, we investigate the implications of a CBDC on financial intermediation by building on the classic model by Diamond and Dybvig (1983), augmented by the presence of a central bank. We select this model because it emphasizes the role of banks in maturity transformation: banks finance long-term projects with demand deposits, which may be withdrawn at a shorter horizon. We find that exploring how a CBDC will interact with maturity transformation is a first-order consideration that has not been thoroughly examined by the literature, often more interested in questions such as the consequences of a CBDC for interest rates, tax evasion, or anonymity (for a review of that literature, see Beniak, 2019). Furthermore, the model by Diamond and Dybvig (1983) allows us to easily explore how bank runs might change with the introduction of a CBDC and to compare those results with previous findings in the literature.

More concretely, we consider a framework in which the CBDC takes the form of demand deposit accounts of the public at the central bank. Like a commercial bank, the central bank holds assets to fund these liabilities, but in contrast to commercial banks, we assume that the central bank cannot invest in long-term projects itself. This might be due to the central bank not having a good technology to screen, monitor, and liquidate productive projects. The central bank can, instead, rely on investment banks to engage in wholesale loans. We derive an interesting equivalence result that shows that the set of allocations achieved with private 
financial intermediation (which, in the Diamond-Dybvig framework delivers an ex-ante first best allocation) can also be achieved with a CBDC, provided competition with commercial banks is allowed.

This equivalence result might seem to vindicate the views of proponents of a CBDC: the socially optimal amount of maturity transformation can still be produced in an economy where the central bank has been opened to all. But our equivalence result has a sinister counterpart. If the competition from commercial banks is impaired (for example, through some fiscal subsidization of central bank deposits or, as we will discuss below, by changes in the structure of possible bank runs), the central bank has to be careful in its choices to avoid creating havoc with maturity transformation.

While the central bank is capable of offering the socially optimal deposit contract, just as commercial banks do, we demonstrate that the rigidity of the central bank's contract with the investment banks leads to different allocations during banking panics. The loan to the investment bank is not callable. This implies that the central bank's indirect investment in the long asset is protected from early liquidation by this, either completely deterring runs on the central bank or making central bank runs less likely than runs on the commercial banking sector. Depositors internalize this feature and exclusively deposit with the central bank. That is, due to the rigidity of the central bank's contract with the investment banks, the central bank becomes the monopoly provider of deposits. This monopoly power can endanger the supply of the first-best amount of maturity transformation in the economy by allowing the central bank to deviate from offering the socially optimal deposit contract.

Our paper is related to several important branches of monetary economics. In terms of money and banking theory, we are, obviously, closest to Diamond and Dybvig (1983), and all the subsequent literature that follows this seminal paper. Our main equivalence result resembles some aspects of Brunnermeier and Niepelt (2019), who show the equivalence of private and public monies in quite a different environment without maturity transformation. By contrast, we highlight, in particular, the equivalence of financial arrangements in terms of maturity transformation, a novel result in the literature.

There is also an emerging literature on CBDC. In Keister and Sanches (2019), banks are financially constrained. Since both central bank money and private bank deposits can be used in exchange, a liquidity premium on bank deposits appears in equilibrium. This premium affects the level of aggregate investment. While a CBDC promotes efficiency in exchange, it also crowds out banks' deposits, raises banks' funding costs, and decreases investment. Related ideas are also explored by Böser and Gersbach (2019). This paper distinguishes itself from Brunnermeier and Niepelt (2019), Keister and Sanches (2019), and Böser and Gersbach (2019) by also discussing allocations under banking panics. 
The rest of the paper is organized as follows. Section 2 frames the current discussion within the historical background. Central banks have been involved before in the business of allowing deposits and by extending loans to the public. In fact, the sharp separation between central banks and the members of the public is a relatively recent phenomenon. Section 3 introduces our model of a central bank open to all. Section 4 defines and characterizes the equilibrium of the economy. Section 5 analyzes bank runs. Section 6 presents some discussion of the robustness of our results. Section 7 offers concluding remarks.

\section{Historical Background}

Historically, many central banks have allowed deposits by and extended loans to firms and private citizens at large. Often, these activities were considered more important for the central banks than the conduct of monetary policy, both in terms of daily operations and the priorities of the top management. Indeed, many governments saw the positive impact on economic growth of a central bank's commercial activities -namely, the supply of demand deposits, the creation of credit, the integration of payment systems, etc.- as the motivation for the creation of such institutions in the first place.

Perhaps the most famous case of a central bank engaged in commercial activities is the Bank of England. This institution, established in 1694 as a privately owned limited-liability corporation, was given "the right to maximise its profits through undertaking a general banking business, including through issuing paper money, taking deposits, lending on mortgages and dealing in bills of exchange as well as gold and silver" (Kynaston, 2017, p. 5). The Bank of England vigorously pursued such a goal for over two centuries, encroaching on the business of other commercial banks through direct competition and the lobbying effort with Parliament at Westminster for additional legal privileges to protect its private businesses against potential competitors.

In the U.S., both the First and Second Banks of the United States participated actively in the borrowing and credit markets (Cowen, 2000, and Knodell, 2017). In fact, the bank war between Andrew Jackson and Nicholas Biddle was linked directly to the operations of the Second Bank of the United States with firms and merchants, which Jackson considered favored his political rivals (Remini, 2017).

Sometimes, the commercial activities of central banks were so large that they became the dominant players in the borrowing and lending markets. For example, in 1900, the Bank of Spain (Banco de España), with 58 branches that covered all major towns across the nation, held $68 \%$ of total assets and $73 \%$ of all demand deposits in the Spanish financial sector (Martín-Aceña, 2017, 2018). In Figure 1, we plot the assets and liabilities of the Bank of 


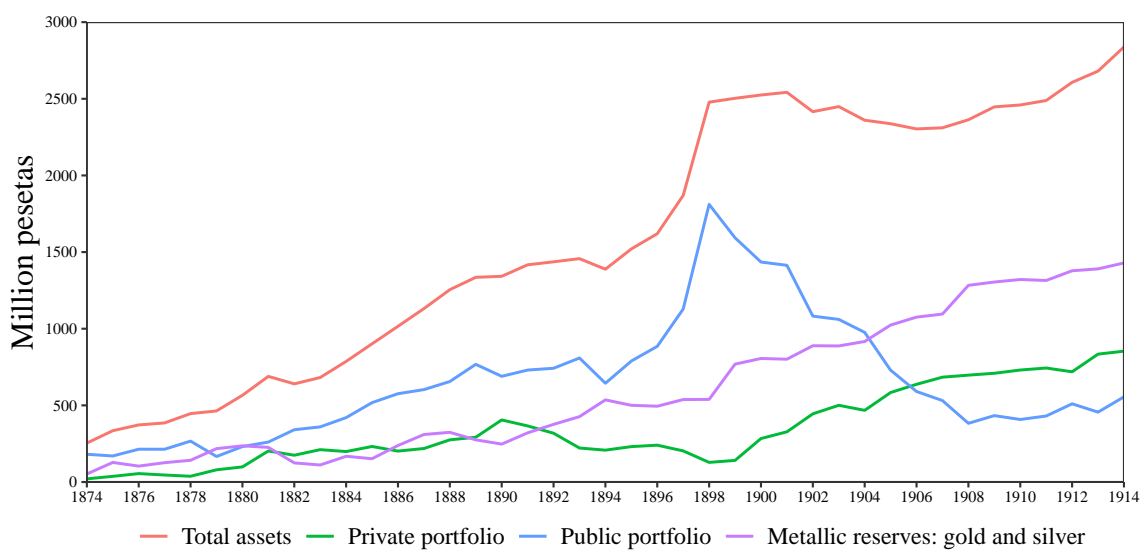

(a) Assets

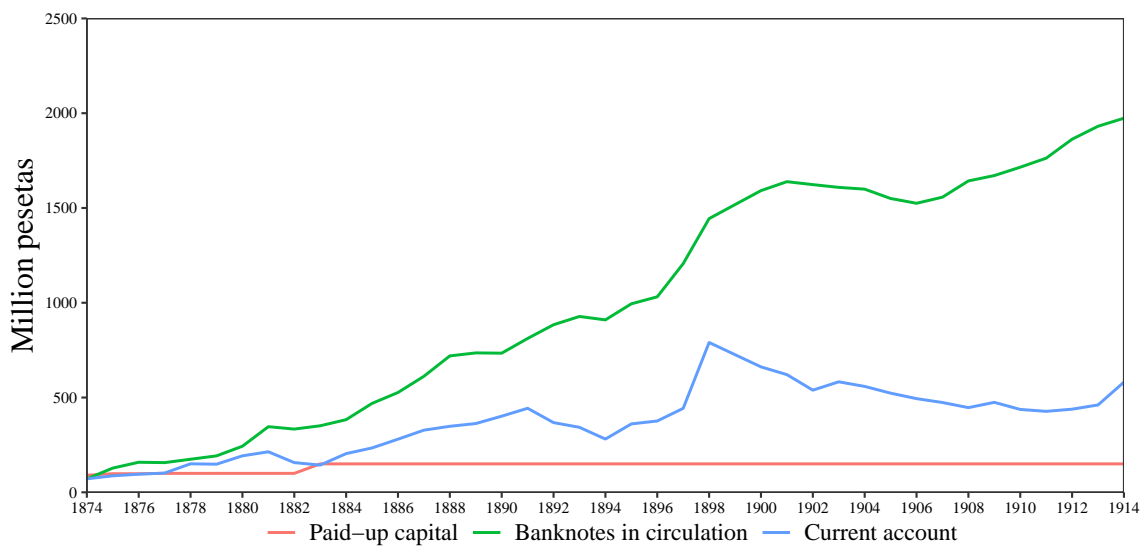

(b) Liabilities

Figure 1: Banco de España, Assets and Liabilities, 1874-1914.

Spain from 1874 to 1914. Panel 1a shows how, by the start of the 20th century, the bank's private portfolio of loans was larger than the public portfolio of treasury bonds. We can also appreciate, in panel 1b, the large size of the current accounts (i.e., demand deposits) on the liabilities side of the bank.

A related development was the existence of postal savings systems. The first such system was the Post Office Savings Bank (POSB) in the United Kingdom, which opened in 1861. In the U.S., such a system operated from 1911 to 1967, reaching by the end of World War II around $10 \%$ of assets of the commercial banking sector. These postal savings systems took advantage of the already-existing network of post offices to offer government-backed deposit accounts and other financial services such as easy and cheap money transfers to private citizens. If we think about a consolidated public-sector balance sheet, deposits at a postal savings system are fully equivalent to deposits at a central bank: they are deposits 
in two different agencies of the same public sector. Political-economic constraints, however, may make such full equivalence break down in practice (for instance, if a government treats profits and losses from a postal savings systems differently from profits and losses from a central bank). ${ }^{3}$

The sharp distinction between a central bank operating only with primary depository institutions and commercial banks dealing with members of the public at large is, to no small extent, a post-WWII development. This move was induced, among other reasons, by the governments's desire to directly control discretionary monetary policies once the gold standard had disappeared. ${ }^{4}$

These new economic conditions led to the nationalization of many central banks, such as the Bank of England in 1946 and the Bank of Spain in 1962, regardless of the political inclination of governments (left-leaning in the U.K. in 1946, right-wing authoritarian in Spain in 1962). But, even today, one can trade shares of many central banks on stock exchanges, including the Swiss National Bank (see Figure 2 for the daily price of this stock since 2001) and the Bank of Japan. Although these shares come with severe voting rights limitations, their active trading is proof that central banks used to be engaged in a very different set of activities from the pure conducting of conventional monetary policy.

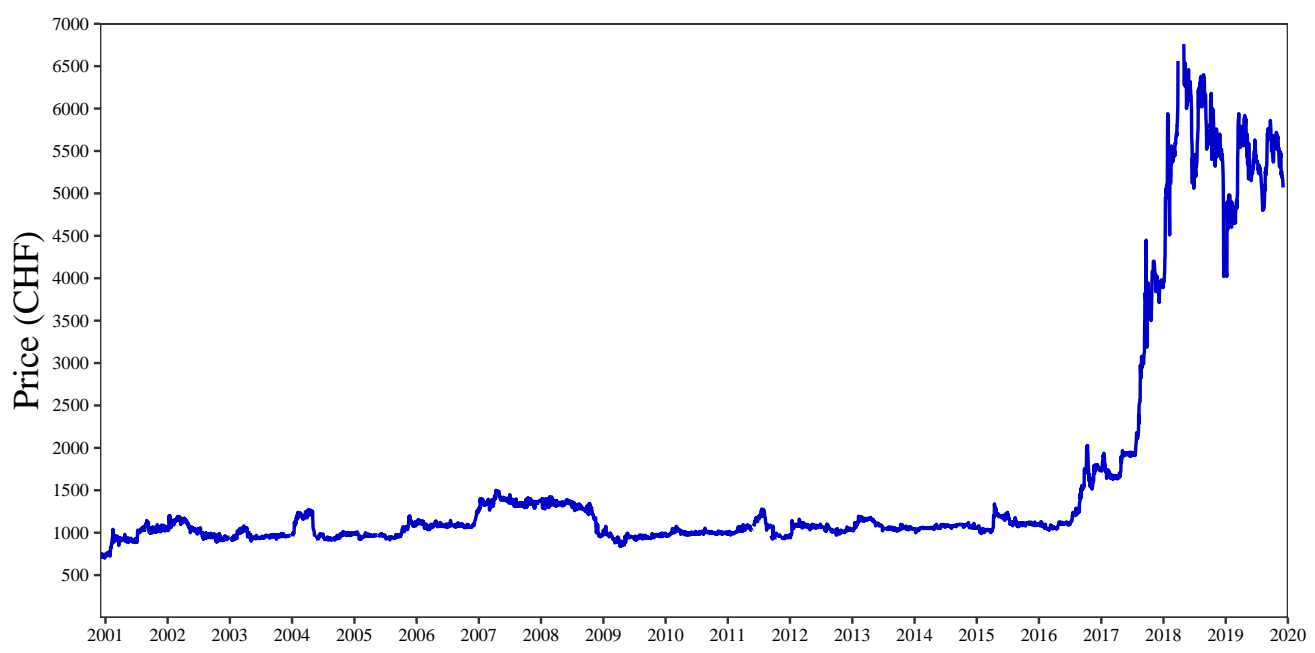

Figure 2: Swiss National Bank daily share price

\footnotetext{
${ }^{3}$ Governments across the world also often own controlling stakes in commercial banks. However, those banks keep a separate corporate structure subject to regular private law and, thus, are not equivalent to postal systems, which are usually integral parts of the public sector and subject to public law.

${ }^{4}$ Also, as economies grew, maintaining central bank facilities open to the public at large became increasingly challenging from an operational perspective. This was, let us remember, the time before the arrival of the internet and cheap computing. Commercial banks, in comparison, found that economic growth allowed them to gain size and offer more attractive terms to a wide range of consumers, eroding the role of central banks in providing retail services and payment facilities.
} 
The arrival of digital money has reopened the debate about the role of central banks. First, CBDCs have become feasible. Second, the internet allows a central bank to skip building an extensive network of branches, either directly or in cooperation with existing commercial banks. Both factors suggest that we can, and very likely will, revisit the sharp separation wall between central banks and the public at large. But, for such an endeavor, we require a formal economic model.

\section{A Model of Banking}

Our benchmark economy builds on the canonical banking model by Diamond and Dybvig (1983). This framework is particularly suitable for our investigation because it places the role of banks as providers of valuable maturity transformation services at the very center of the model. Thus, we can use our environment to investigate how the presence of a CBDC, and the subsequent opening of central bank deposits to the public at large, affects such financial intermediation and the bank runs that might break it down.

However, we will depart from the standard version of the model, as presented in Allen and Gale (2009), on two points. First, less importantly, we will introduce a distinction between commercial and investment banks. Second, more relevantly, we will add a governmentcontrolled central bank.

Why do we distinguish between commercial and investment banks? This distinction will be convenient to clarify our results, and nothing of substance beyond some intuition is lost by eliminating it (we could rework our main propositions by allowing a richer set of contracts between banks and depositors and interbank loans). Also, dealing separately with each type of bank opens the door to simple extensions of the model where there are differences in regulation between commercial and investment banks, a feature of many regulatory frameworks across time.

Why do we need to introduce a central bank? Mechanically, since we are interested in CBDCs, we need a central bank. But there is a more subtle point at play. One primary purpose of our analysis is to verify that the implementation of an efficient allocation can be accomplished in an arrangement in which a government-controlled institution competes with private banks for deposits. Such discussions could be logically separated from any consideration of digital money, even if digital money makes the discussion more salient by overcoming previous logistic hurdles that opening central bank balance sheets to the public could bring. The potential equivalence result that can emerge from our analysis can be viewed as an implementation exercise that we think is relevant for the discussions regarding the role of central banks in the provision of deposit accounts to the public at large. 
Let us then introduce the main blocks of our model. There are three periods indexed by $t=0,1,2$. In each period, there is a single good that can be used for either consumption or investment. The economy is populated by consumers, commercial and investment bankers, and a central bank. Let us now describe each type of agent in turn. Subsections 3.1 and 3.2 are essentially as described in Allen and Gale (2009), except for introducing investment banks in subsection 3.2.

\subsection{Consumers}

There is a $[0,1]$-continuum of ex-ante identical consumers, each of whom has an endowment of one unit of the good in period 0. The consumer's utility function is defined by:

$$
U\left(c_{1}, c_{2}\right)=\left\{\begin{array}{c}
u\left(c_{1}\right) \text { with probability } \lambda, \\
u\left(c_{2}\right) \text { with probability } 1-\lambda,
\end{array}\right.
$$

where $c_{1} \in \mathbb{R}_{+}$denotes consumption in period 1 and $c_{2} \in \mathbb{R}_{+}$denotes consumption in period 2. In other words, with probability $\lambda \in(0,1)$, an agent is an early (impatient) consumer who values consumption in period 1 ; with probability $1-\lambda$, an agent is a late (patient) consumer who values consumption in period 2 . The utility function $u: \mathbb{R}_{+} \rightarrow \mathbb{R}_{+}$is strictly increasing, strictly concave, and continuously differentiable.

This setting has an interpretation where ex-ante identical agents are subject to idiosyncratic consumption shocks in $t=1$. Each consumer learns her type (i.e., whether she is an early or late consumer) in period 1, which is private information. This informational asymmetry will prevent banks from discriminating among consumers. In period 1, agents can visit a central location, which occurs sequentially in random order.

Finally, the consumer has access to a storage technology that carries one unit of the good from period 0 into one unit of the good in period 1 and, similarly, one unit of the good from period 1 into one unit of the good in period 2. This technology allows the patient consumer to withdraw her deposit from the bank in period 1 even if she prefers to consume in period 2. This feature will become relevant when we talk about bank runs.

\subsection{Banks}

There are a large number of banks that make investments on behalf of consumers. Banks have access to two types of investment technologies: a short- and a long-term technology. The short-term technology (or short asset) is a constant-returns-to-scale technology that takes one unit of the good at date $t=0,1$ and converts it into one unit of the good at date $t+1$. One 
can think about this technology as storage, such as the vault in the basement of a bank. ${ }^{5}$

The long-term technology (or long asset) is a risk-free constant-returns-to-scale technology that takes one unit of the good in period 0 and transforms it into $R>1$ units of the good in period 2. If the long-term technology is liquidated prematurely in period 1 , then it pays off $\kappa \in(0,1)$ units of the good for each unit invested. One can think about this technology as a productive project that requires some time to yield its fruits, and that is subject to an early liquidation cost.

There are two types of banks: commercial banks and investment banks. Both types of banks can always be found in the central location. In what follows, we use the terms "banker" and "bank" interchangeably. Commercial (also called retail) banks offer demand deposit contracts (to be described momentarily) to consumers and use the proceedings to invest in short and long assets.

In comparison, investment bankers, while also having access to the storage technology and the long assets, only offer contracts contributing non-negative profits in period 2. To put it differently: investment banks do not provide liquidity by offering demand deposits to consumers. All future cash flows from investment banks to a contracting partner (such as the central bank) are already determined in $t=0$, and the contracting partner cannot spontaneously demand payments in $t=1$, as is the case with demand deposits at commercial banks. Consequently, and since the long asset return dominates the short asset returns, investment bankers choose only to operate the long-term technology and maximize period-2 profits.

We include in our interpretation of investment banks not only financial institutions that call themselves by that name, but also industrial banks (historically common in Continental Europe, Japan, and South Korea), and any other investment vehicles, such as retirement funds, whose goals are centered around long-term returns.

\subsubsection{Deposit contracts}

A commercial bank offers a deposit contract $\left(\hat{c}_{1}, \hat{c}_{2}\right) \in \mathbb{R}_{+}^{2}$ to consumers. If the consumer accepts a banker's contract, then she is required to deposit one unit of the good with the banker in period 0 . The banker invests a portion $y$ of the goods in the short-term technology, and the remaining portion $1-y$ is invested in the long-term technology.

The banker promises to pay either $\hat{c}_{1}$ units of the good to a consumer on demand in period 1 or the lower of the amount $\hat{c}_{2}$ and the resources available to the banker, which

\footnotetext{
${ }^{5}$ Notice that this storage technology is the same as the one available to consumers. Banks, however, have the advantage that they can pool the risks of early and late consumers, while individual consumers cannot sign insurance contracts among themselves against their idiosyncratic liquidity risk.
} 
are equally divided across all remaining depositors in period 2. The banker is committed to paying $\hat{c}_{1}$ units to consumers arriving in period 1 either by using the returns from the short-term investment or by liquidating long-term projects until all resources are exhausted. Any leftover resources in period 1 are invested in the short-term investment technology. The banker consumes any leftover resources in period 2 .

We assume that the banker's consumption cannot be negative and that bankers maximize their period-2 consumption per their choice of the deposit contract. Finally, we also assume that bankers are in Bertrand competition when offering deposit contracts to consumers and, thus, make zero profits.

Note that closing the model here, before the introduction of a central bank, would result in the same allocation as in the standard Diamond-Dybvig setup. In equilibrium, the bankers would consume nothing and the expected utility of the consumers is maximized, subject to the feasibility constraints arising from the problem above. As a result, the equilibrium allocation would be first-best efficient ex-ante (even if subject to possible runs ex-post). We refer to the contract associated with the first-best efficient allocation as $\left(c_{1}^{*}, c_{2}^{*}\right)$. Appendix A provides the details.

\subsection{The central bank}

The central bank in our model is a government-controlled institution that has access to the short-term investment technology, but no access to the long asset. The central bank may, however, contract with investment banks. Furthermore, the central bank cannot rely on independent sources of taxation.

\subsubsection{Four properties of the central bank}

The definition above has four components that we need to unpack. First, the central bank is a government-controlled institution. Our definition highlights who effectively controls the central bank, the government, and not who owns the bank legally. Many central banks have complex ownership structures that are a product of historical accidents and political-economic bargainings (think about the convoluted structure of the Federal Reserve System in the U.S.). However, in practice, all central banks in the advanced economies behave similarly regardless of their ownership due to governance rules that place them firmly under the control of the public sector. This is true even if the central banks may enjoy operational independence in the pursuit of goals such as price stability laid down by the legislative branch. ${ }^{6}$

\footnotetext{
${ }^{6}$ For evidence on the irrelevance of ownership structures among 35 OECD central banks, see Bartels et al. (2016).
} 
Second, we allow the central bank to have access to the short-term asset. All central banks have access to storage technologies: a simple visit to the gold vault at the Federal Reserve Bank of New York verifies this point. ${ }^{7}$ Scaling up such storage facilities could be costly, but certainly is well within the capabilities of modern states.

Third, we do not allow the central bank to have access to the long-term asset. This assumption captures the idea that private banks have a comparative advantage in monitoring loans to extract their full return (or, in an alternative formulation, in liquidating non-performing loans à la Diamond and Rajan, 2001). It is reasonable to assume that a central bank does not have access to the same investment opportunities as private banks do, the latter having developed over decades an expertise in screening, monitoring, and liquidating productive projects. ${ }^{8}$ The assumption also makes the economics of our paper more interesting: the central bank cannot be just a simple clone of a commercial bank on a larger scale.

Fourth, the central bank is not fiscally backed, either directly, for example, through the proceeds of seigniorage, or indirectly through independent sources of taxation, such as a subsidy from the general-government budget. In other words, the central bank has access only to goods provided by consumers in period 0 or the proceeds from investments in the short-term technology or (as we will see soon) with the investment banks. Conversely, the commercial banks are not taxed by any special levy that might make their deposits unattractive (an actuarially fair deposit insurance does not violate this condition, though, as it does not change the expected value of the deposits at a commercial bank).

This fourth assumption will be key for our analysis and, yet, at the same time, the most fragile. If a central bank had fiscal backing, it would have an advantage with respect to commercial banks that would render the rest of the analysis somewhat trivial. At the same time, political-economic considerations are likely to be a first-order consideration in the actual running of a central bank open to all. Many political groups will lobby the bank to change its borrowing and lending policies so as to achieve the group's preferred outcomes, even if this action requires fiscal backing. ${ }^{9}$ Similarly, considerations about the ownership structure

\footnotetext{
${ }^{7}$ In fact, such a visit verifies the existence of the storage technology regarding an important but subtle point: the vault allows for the storage of a real good, gold. The Diamond-Dyvig model is built around real goods, not nominal contracts.

${ }^{8}$ The assumption could be relaxed by allowing the central bank to have access to the long-term asset with a return $R^{*}<R$. Since we will show an equivalence result where, under certain circumstances, the central bank can circumvent its investment limitations, such an extension would only strengthen our argument.

${ }^{9} \mathrm{An}$ example of such lobbying, even with the current more limited scope of actions by central banks, is the recent open letter of a group of academics and social groups to Christine Lagarde asking the ECB to act on climate change through a commitment "to gradually eliminating carbonintensive assets from its portfolios" (see http://www.positivemoney.eu/wp-content/uploads/2019/11/ Open-Letter-to-Christine-Lagarde-on-climate-change.pdf).
} 
of central banks and dividend payments, which we argued above are mainly inconsequential at the moment, might resurface.

\subsubsection{Deposits at the central bank}

The central bank can offer the same kind of deposit contract $\left(d_{1}, d_{2}\right)$ described above to consumers, i.e., it competes for deposits with the commercial banks. Specifically, in exchange for one unit of the good at date 0 , the central bank allows depositors to withdraw either $d_{1} \in \mathbb{R}_{+}$units in period 1 or $d_{2} \in \mathbb{R}_{+}$units in period 2 .

From our previous discussion, it is clear the central bank is in a disadvantaged position to compete with the commercial banks. Lacking access to long-term investment opportunities, a central bank might seem less capable of engaging in liquidity transformation. We will show that, in spite of this disadvantage, the central bank can still compete in the retail deposit market by contracting with the investment banks to access the long-term technology, referred to as wholesale deposits. Implicit in this step is the assumption that a central bank will not face frictions in the wholesale deposit market (such as a lack of information or the expertise to operate in it). Given that central banks already participate in this market, for example, with repo operations, this assumption is empirically plausible.

In period 0, all bankers and the central bank play a simultaneous game, referred to as the demand deposit game, when offering both retail and wholesale deposit contracts. After observing the contracts posted by all bankers and the central bank, all consumers make their deposit decisions. The central bank then deposits a portion $1-x$ of each deposited unit with the investment banks, investing the remainder $x \in[0,1]$ in the short-term technology.

Let $\ell_{2}$ be the contract between the central bank and the representative investment bank. That is, $\ell_{2}$ describes the real liabilities of the investment bank per unit of goods received by the central bank in period 0 . The private investment bank commits to investing all funds received by the central bank in the long asset.

In period 2, an investment bank receives the proceeds from investing in the long-term technology and makes its second-period payment $\ell_{2} \in \mathbb{R}_{+}$to the central bank per unit deposited by the central bank in period 0 . Investment banks only offer contracts $\ell_{2}$ to the central bank, if they result in non-negative profits, i.e., if

$$
\ell_{2} \leq R
$$

Let $f \in[0,1]$ denote the fraction of consumers who deposit with the central bank in period 0. Because each consumer deposits one unit, the central bank receives $f$ units from all depositors. Let $\alpha \in[0,1]$ denote the fraction of depositors who decide to withdraw in period 
1. The budget constraints for the central bank in periods 1 and 2 are:

$$
\alpha d_{1} \leq x
$$

and

$$
(1-\alpha) d_{2} \leq \ell_{2}(1-x)+x-\alpha d_{1}
$$

respectively.

Note that in our description of the central bank's behavior, we are not assuming a particular objective function (such as profit or social welfare maximization) beyond the requirement that the central bank satisfies its budget constraints (i.e., no fiscal backing). In the tradition of public finance, we will postulate below an equilibrium that is indexed by the central bank choice of deposit contract (regardless of how it is determined) and characterize it for a class of relevant contracts.

\subsection{The consumer's problem}

Consider now the consumer's problem. An individual consumer must decide whether to deposit with the central bank, consuming either $c_{1}=d_{1}$ upon withdrawal in period 1 or $c_{2}=d_{2}$ in period 2, or with a commercial bank, consuming either $c_{1}=\hat{c}_{1}$ upon withdrawal in period 1 or $c_{2}=\hat{c}_{2}$ in period 2. Consumers choose the contract that delivers the highest ex-ante expected utility. If both contracts offer the same utility, then some fraction $f$ will pick the central bank, and the remaining fraction will pick the commercial banks. In that case, the fraction $f$ is indeterminate.

To complete the description of consumer behavior in period 0 , we need to specify deposit decisions in the initial period and withdrawal strategies in the intermediate period. Let $h_{i} \in\{0,1\}$ denote the deposit decision of consumer $i \in[0,1]$, where $h_{i}=0$ represents depositing with a commercial bank and $h_{i}=1$ represents depositing with the central bank. Let $h=\left\{h_{i}\right\}_{i \in[0,1]}$ denote the profile of deposit choices in the initial period.

A withdrawal strategy for consumer $i$ is a variable $\sigma_{i} \in\{1,2\}$ that indicates the date at which consumer $i$ withdraws from the banking system. An early consumer always withdraws in the intermediate period with probability one. A late consumer may choose to withdraw early, depending on her beliefs about other patient consumers' actions. Let $\sigma=\left\{\sigma_{i}\right\}_{i \in[0,1]}$ denote the complete profile of withdrawal strategies, and let $\sigma_{-i}$ denote the profile of strategies for all investors except $i$. In period 1 , consumer $i$ selects a best response $\sigma_{i}$ in the withdrawal game, given her expectations of other agents' strategies $\sigma_{-i}$. 


\section{Equilibrium}

We are now in a position to formally define an equilibrium for the economy with a central bank. In particular, we restrict attention to symmetric equilibria, where all investment banks and all commercial banks use the same contract.

Definition 1 An equilibrium is a contract $\ell_{2}$ between the central bank and the representative investment bank, a demand-deposit contract $\left(\hat{c}_{1}, \hat{c}_{2}\right)$ for the representative commercial bank, a demand-deposit contract $\left(d_{1}, d_{2}\right)$ for the central bank, deposit decisions $h \in\{0,1\}$ in the initial period, a strategy profile $\sigma \in\{1,2\}$ for the withdrawal game in the intermediate period, a fraction $\alpha \in[0,1]$ of depositors who withdraw in period 1 , and a fraction $f \in[0,1]$ of consumers depositing with the central bank such that:

1. In period 0 , given the contracts $\left(\hat{c}_{1}, \hat{c}_{2}\right)$ and $\left(d_{1}, d_{2}\right)$, each consumer $i \in[0,1]$ optimally deposits one unit of the good with a financial institution by selecting the contract that offers the highest expected utility. The strategy profile $\sigma$ is a Nash equilibrium of the withdrawal game in period 1.

2. Each commercial bank chooses the contract $\left(\hat{c}_{1}, \hat{c}_{2}\right)$ to maximize profits in period 2 , given $\left(d_{1}, d_{2}\right)$.

3. Each investment bank offers the contract $\ell_{2}$, provided it satisfies the non-negative profit condition (1).

4. The budget constraints (2) and (3) for the central bank hold with equality, given the strategy profile $\sigma$.

5. Withdrawals in period 1 satisfy $\alpha=1-\int_{\left\{i \in[0,1]: \sigma_{i}=2\right\}} d i$.

6. Initial deposits $f$ at the central bank satisfy $f=\int h_{i} d i$.

The previously described economy represents an arrangement with a central bank that does not necessarily act as a self-interested agent. In our analysis, the central bank competes with the private banks for deposits from consumers and can access the long-term technology by contracting with the investment banks. The existence of a non-profit-maximizing entity in the competition for demand deposit contracts could lead private banks to behave in a different way than what would be expected from them with standard Bertrand competition. In particular, $0<f<1$ can only occur if consumers are indifferent between depositing at the central bank or at a commercial bank. 
Nevertheless, we next show that the central bank is capable of replicating the socially optimal contract by correspondingly investing in the investment banking sector (recall that Appendix A characterizes the socially optimal contract commercial banks offer in the absence of a central bank).

Lemma 4.1 (Replication of the Optimal Contract) The central bank replicates the socially optimal commercial bank contract by setting $x=y^{*}, d_{1}=c_{1}^{*}, d_{2}=R\left(1-y^{*}\right) / 1-\lambda$. To offer this optimal contract, the central bank requires $l_{2}=R$, implying zero profits to investment banks.

Proof. [Lemma 4.1] The allocation $x=y^{*}, d_{1}=c_{1}^{*}, d_{2}=R\left(1-y^{*}\right) / 1-\lambda$ with $l_{2}=R$ is feasible by (1), (2), and (3) and with $\alpha=\lambda$ and optimal by (A.4), (A.5) and (A.6).

Our next result shows that, in equilibrium, the socially optimal contract is always offered by some bank.

Proposition 4.1 In equilibrium, the socially optimal contract is offered either by the commercial banks or the central bank or both. If both the central bank and the commercial bank have customers, $f \in(0,1)$, then both banks are offering the optimal contract.

Note that if only commercial banks offer the optimal contract, they absorb the entire deposit market $f=0$. Vice versa, if only the central bank offers the optimal contract $f=1$. If, however, both kinds of banks offer the optimal contract, then by indifference, every $f \in[0,1]$ is an equilibrium.

Proof. [Proposition 4.1] We first show that, in equilibrium, all commercial bankers that have depositors as customers make zero profits and offer the socially optimal contract.

Let $\tau$ denote the commercial bank's profit. Consider the following depositor utility maximization problem, which guarantees profit $\tau$ :

$$
V(\tau)=\max _{\left(y, c_{1}, c_{2}\right) \in \mathbb{R}_{+}^{3}}\left[\lambda u\left(c_{1}\right)+(1-\lambda) u\left(c_{2}\right)\right]
$$

subject to $0 \leq y \leq 1, \lambda c_{1} \leq y$, and

$$
(1-\lambda) c_{2} \leq R(1-y)+y-\lambda c_{1}-\tau
$$

Let $\left(y(\tau), c_{1}(\tau), c_{2}(\tau)\right)$ denote the solution to this problem. The value function $V(\tau)$ gives the maximum expected utility for the consumer for each profit level $\tau \in \mathbb{R}_{+}$for the banker. Given our assumptions on preferences and technologies, we obtain a unique interior solution characterized by:

$$
u^{\prime}\left(\frac{y}{\lambda}\right)=R u^{\prime}\left(\frac{R(1-y)-\tau}{1-\lambda}\right)
$$


which implicitly defines $y(\tau)$. Then, we have $c_{1}(\tau)=\frac{y(\tau)}{\lambda}$ and $c_{2}(\tau)=\frac{R[1-y(\tau)]-\tau}{1-\lambda}$.

The envelope theorem implies $V^{\prime}(\tau)<0$ for any $\tau>0$. All depositors contract only with those banks that offer the highest utility-yielding contract. All commercial banks internalize that the banks that offer the best contract absorb the entire market of deposits. If the commercial banker's profit is non-zero $\tau>0$, then any banker who offers a contract $\left(y\left(\tau^{\prime}\right), c_{1}\left(\tau^{\prime}\right), c_{2}\left(\tau^{\prime}\right)\right)$ with $0<\tau^{\prime}<\tau$ will end up attracting all depositors and, therefore, make non-zero profits. Due to this price competition, we can only obtain an equilibrium for $\tau \rightarrow 0$. The result follows by $\left(y(\tau), c_{1}(\tau), c_{2}(\tau)\right) \rightarrow\left(y^{*}, c_{1}^{*}, c_{2}^{*}\right)$ pointwise: if $f<1$, then the commercial banks with customers offer the optimal contract. Fix $V^{*} \equiv \lim _{\tau \rightarrow 0} V(\tau)$, the value implied by the optimal contract.

What if the central bank also attracts some, and potentially all customers, $f \in(0,1]$ ? We next show that in this case, the central bank must also be offering the optimal contract.

By Lemma 4.1, the central bank is capable of offering the socially optimal commercial bank contract. Since the central bank does not have access to better technology, and by $l_{2} \leq R$ (otherwise the investment banking sector runs losses) and $\alpha \geq \lambda$, the central bank cannot offer a contract better than the socially optimal commercial bank contract.

Suppose the central bank offers a contract $\left(d_{1}, d_{2}\right)$ subject to the feasibility constraints (1), (2), and (3). Such a contract will result in the expected utility $\lambda u\left(d_{1}\right)+(1-\lambda) u\left(d_{2}\right)$ for the consumer. Because $V(\tau)$ is continuous, and decreasing, there exists a profit $\tau_{c} \geq 0$ such that the commercial bank can replicate the central bank contract $V\left(\tau_{c}\right)=\lambda u\left(d_{1}\right)+$ $(1-\lambda) u\left(d_{2}\right)$. If $\tau_{c}=0$, the central bank is offering the socially optimal contract. In that case, the commercial bank can make the central bank customers indifferent by also setting the optimal contract, achieving by this any $f \in[0,1]$ in equilibrium. If $\tau_{c}>0$, then the central bank is not offering the socially optimal contract. Thus, the commercial bank can lure the central bank's customers away $(f=0)$ by offering a contract that implies a profit $\tau<\tau_{c}$. Other commercial banks can further undercut the profit and again the socially optimal contract is offered in equilibrium as $\tau \rightarrow 0$ via Bertrand competition. Further, since the central bank anticipates this competition, it may set the socially optimal contract in the first place.

The previous result shows how competitive forces act to limit the extent to which the investment banks can extract surplus from the central bank. For any $l_{2}<R$, the central bank fails to offer the socially optimal contract. Due to Bertrand competition with the commercial banking sector, the central bank attracts zero deposits, which leads to zero initial investment in the investment banking sector. The competition between the commercial banking sector and the central bank for deposits disciplines the investment banking sector.

A central bank could break such an arrangement by insisting on accepting only the best 
investment bank contracts or even by contracting with commercial banks. However, we could imagine political circumstances preventing a central bank from proceeding in such a manner, and we have not insisted on this in our definition of the equilibrium.

Lemma 4.1 and Proposition 4.1 show that, since a central bank is capable of replicating the socially optimal contract by relying on the investment banking sector, the presence of a CBDC (or, more generally, of a central bank "open to all") can still deliver the same maturity transformation that commercial banks do in its absence. Moreover, if the socially optimal contract is offered and if all depositors behave according to their types (i.e., consumers withdraw if and only if impatient), then the socially optimal contract is indeed attained. This result holds independently of whether the contract is offered by the commercial bank or the central bank.

This equivalence result backs up some of the statements of the defenders of a CBDC: in equilibrium, we still obtain the socially optimal amount of maturity transformation. However, as we discussed in the introduction, this equivalence result has a sinister counterpart. If the conditions behind Lemma 4.1 and Proposition 4.1 are broken, for instance, because the central bank receives fiscal backing, the competitive forces that create the right amount of maturity transformation disappear and the central bank must tread carefully in deciding how to avoid creating suboptimal levels of maturity transformation. While the central bank can do so, nothing in the model is ensuring such an outcome. In particular, there is the threat that, in the absence of the counterbalancing forces of competition, political-economic mechanisms might lead the central bank to outcomes that are clearly suboptimal.

\section{$5 \quad$ Runs}

In the previous section, we show a fundamental equivalence result between the deposit contracts of commercial and central banks. Nevertheless, the payments written in the deposit contract were feasible only if depositors behaved according to their types. But what if they do not do so?

The contract offered by the central bank is not identical in functionality to the contract offered by the commercial banks. The central bank contract is more rigid, since the central bank cannot call its loan to the investment bank to liquidate early. In other words, the central bank is constrained to serve up to the returns of the short asset and not more.

In comparison, the commercial bank has direct control over its investment: the commercial bank can serve depositors in the interim period on demand by liquidating not only the short but also the long asset. Hence, once we allow for banking panics where depositors mimic the impatient type and withdraw early to secure their deposits, the rigidity of the central bank 
contract has implications for depositor incentives and equilibrium outcomes. ${ }^{10}$

\subsection{Commercial bank runs}

Following Diamond and Dybvig (1983), we now show how commercial banks are prone to self-fulfilling runs. Consider a depositor who has deposited with the commercial bank. By Proposition 4.1, we know that this bank must be offering the socially efficient contract $\left(c_{1}^{*}, c_{2}^{*}\right)$. Assume that, at $t=1$, this depositor learns that she is patient. Since her type is unobservable, she may nevertheless act as if she was impatient and decide to withdraw. When would she do this?

If only a measure $\alpha=\lambda$ of depositors withdraw, the payoffs are exactly as in her contract. If, however, patient depositors also withdraw, i.e., $\alpha \in(\lambda, 1]$, the payoffs to rolling over and withdrawing deviate from the payoffs promised in the contract. This is because the commercial bank has committed to paying the short-term coupon $c_{1}^{*}$ to every depositor who demands back her deposit in $t=1$. To finance withdrawals above $\lambda$, the commercial bank needs to liquidate the long-term asset, which reduces payoffs to those depositors who roll over.

We say that a run on the commercial bank occurs if the commercial bank is forced to liquidate not only its investment in the short-term but also its investment in the long-term asset to satisfy short-term withdrawals. That is, if $\alpha c_{1}^{*}>y^{*}+\left(1-y^{*}\right) \kappa$, or equivalently if

$$
\{\text { Run on Commercial Bank }\} \quad \Leftrightarrow \quad\left\{(\alpha-\lambda) c_{1}^{*}>\left(1-y^{*}\right) \kappa\right\}
$$

In the case of a run, depositors who roll over receive zero, and depositors who withdraw receive the payoff $c_{1}^{*}$ only with a certain likelihood due to rationing. The interpretation here is that $\alpha>\lambda$ depositors queue at the commercial bank to receive their deposit back. As explained above, the bank serves depositors by using short assets and liquidating longterm assets. If there are not enough long-term assets to liquidate, the commercial bank chooses a random subset of agents $\frac{y^{*}+\left(1-y^{*}\right) k}{\alpha c_{1}^{*}}$ in the queue to whom it serves the payment $c_{1}^{*} \cdot{ }^{11}$ Conditional on no run, the depositors' payoffs are as in the original contract.

The payoff matrix is, then:

\footnotetext{
${ }^{10}$ We are implicitly assuming here that commercial banks cannot replicate the rigidity of the central bank contract by depositing in the investment banks and using interbank loans. In that way, the commercial banks would be indirectly investing in the long asset, while committing not to liquidate the long asset in the interim period. While this is an interesting avenue of investigation, in practice, most regulatory systems severely limit the ability of commercial banks to build this class of commitment devices.

${ }^{11}$ Goldstein and Pauzner (2005) make this assumption about which depositors receive payments to avoid the possible complications of a sequential service constraint pointed out by Wallace (1988).
} 


\begin{tabular}{l||c|c} 
Event/Action & withdraw & roll-over \\
\hline no run, & $u\left(c_{1}^{*}\right)$ & $u\left(\frac{R\left[\left(1-y^{*}\right)-(\alpha-\lambda) c_{1}^{*} / \kappa\right]}{1-\alpha}\right)$ \\
\hline run & $\frac{y^{*}+\left(1-y^{*}\right) k}{\alpha c_{1}^{*}} \cdot u\left(c_{1}^{*}\right)$ & 0 \\
\hline
\end{tabular}

Thus, we find a classic strategic complementarity in actions: conditional on a bank run, the payoff from withdrawing exceeds the payoff from rolling over and withdrawing deposits is optimal. Vice versa, if only a few consumers withdraw, $\alpha=\lambda$, then the payoff from rolling over is larger, $c_{1}^{*}<c_{2}^{*}$ (recall Appendix A); thus, for a patient depositor it is optimal to roll over her deposit. We summarize this idea in the proposition below.

Proposition 5.1 (Commercial Bank Multiple Equilibria: Diamond and Dybvig (1983)) The withdrawal game of commercial bank depositors has two pure equilibria. There is a good equilibrium in which all patient depositors roll over their deposit, $\alpha=\lambda$, and the socially optimal contract is attained. But there is also a bank run equilibrium, where all patient depositors panic and withdraw, $\alpha=1$. In the latter case, the socially optimal contract is not attained.

\subsection{Central bank runs}

Runs on central banks are, in contrast, a very different entity. During a bank panic, the central bank cannot call the loan to the investment bank and can, therefore, only serve withdrawals up to the returns stemming from the short asset. In other words, the contract offered by the central bank is not a demand-deposit contract: it exhibits rigidity.

This constraint has two consequences. First, the payoffs under a run on the central bank differ from payoffs under a run on the commercial bank. In the social optimum, the central bank invests $y^{*}=\lambda c_{1}^{*}$ in the short asset and the remaining $1-y^{*}$ in the investment bank loan. Thus, the central bank cannot serve more than a measure $y^{*}$ of cash withdrawals, while the commercial bank can serve up to measure $y^{*}+\left(1-y^{*}\right) \kappa$, financed via early liquidation of the long asset.

Second, the incident that triggers a run on the central bank differs from the triggering event for a run on a commercial bank. A run on the central bank occurs if $\alpha c_{1}^{*}>y^{*}$ or, equivalently, if:

$$
\{\text { Run on Central Bank }\} \quad \Leftrightarrow \quad\{\alpha>\lambda\}
$$

In the incident of a run, the central bank can allocate only real goods of quantity $y^{*}$ to measure $\alpha$ of agents. As in the commercial bank case, we assume that depositors queue and receive the original claim of $c_{1}^{*}$ units if and only if they are sufficiently early in the queue, i.e., with likelihood $\lambda / \alpha$. Since the central bank cannot liquidate the investment in the long 
asset, how do we treat the remaining depositors who were not served so far? There are two ways the central bank can proceed from here. ${ }^{12}$

\subsubsection{Punishment}

The central bank can decide to punish depositors who contribute to the run. More concretely, the central bank will not pay any depositors beyond measure $\lambda$ who try to withdraw, and all returns earned in $t=2$ will go exclusively to depositors who roll over. Then, the payoff matrix becomes:

\begin{tabular}{l||c|c} 
Event/Action & withdraw & roll-over \\
\hline no run, $\alpha=\lambda$ & $u\left(c_{1}^{*}\right)$ & $u\left(\frac{R\left(1-y^{*}\right)}{1-\lambda}\right)$ \\
\hline run, $\alpha>\lambda$ & $\frac{\lambda}{\alpha} \cdot u\left(c_{1}^{*}\right)+\left(1-\frac{\lambda}{\alpha}\right) \cdot 0$ & $u\left(\frac{R\left(1-y^{*}\right)}{1-\alpha}\right)$ \\
\hline
\end{tabular}

The rigidity of the contract achieves the result that, under higher withdrawals, a depositor who rolls over is rewarded when withdrawals are high, since she shares the total returns with fewer depositors. For $\alpha>\lambda$,

$$
u\left(\frac{R\left(1-y^{*}\right)}{1-\alpha}\right)>u\left(\frac{R\left(1-y^{*}\right)}{1-\lambda}\right) .
$$

In addition, during a run, due to punishment and queuing, a withdrawing depositor receives $c_{1}^{*}$ only with a certain likelihood:

$$
\frac{\lambda}{\alpha} u\left(c_{1}^{*}\right)<u\left(c_{1}^{*}\right)
$$

Last, we know $c_{1}^{*}<c_{2}^{*} \equiv \frac{R\left(1-y^{*}\right)}{1-\lambda}$, since the utility function is concave and by $R>1$ and equation (A.6). Altogether, for $\alpha>\lambda$ :

$$
\frac{\lambda}{\alpha} u\left(c_{1}^{*}\right)<u\left(\frac{R\left(1-y^{*}\right)}{1-\alpha}\right)
$$

Under punishment, the resulting payoff structure deters a run from happening, and the strategic complementarity of actions is broken. To patient depositors, rolling over is dominant, and, in equilibrium, only impatient depositors withdraw. Formally, we have the following proposition.

Proposition 5.2 (Central Bank Equilibria: No Run under Punishment) If the central bank punishes depositors who contribute to a run, then the withdrawal game of central

\footnotetext{
${ }^{12}$ Recall that the central bank does not have fiscal backing and, this being a real model, it cannot issue fiat money to meet depositors. Fernández-Villaverde et al. (2020) relax the latter assumption by building a nominal model of CBDCs.
} 
bank depositors has a unique equilibrium. All patient depositors roll over, and only impatient depositors withdraw. Runs on the central bank do not occur. The socially optimal contract is always attained when offered.

The effect of the contract's rigidity is reminiscent of a regulatory intervention such as a mandatory stay for depositors that enforces a halt of service. Diamond and Dybvig (1983) already show that the combination of punishment and a regulatory intervention (here the contract rigidity) can deter runs from happening.

\subsubsection{Equal treatment}

Now assume instead that the central bank does not punish depositors who contribute to the run. Instead, depositors beyond measure $\lambda$ who could not be served in the interim period are treated as if they had rolled over their deposit. Consequently, the payoff to rolling over becomes independent of what other depositors do. Then, the resulting payoff matrix becomes:

\begin{tabular}{l||c|c} 
Event/ Action & withdraw & roll-over \\
\hline no run, $\alpha=\lambda$ & $u\left(c_{1}^{*}\right)$ & $u\left(\frac{R\left(1-y^{*}\right)}{1-\lambda}\right)$ \\
\hline run, $\alpha>\lambda$ & $\frac{\lambda}{\alpha} \cdot u\left(c_{1}^{*}\right)+\left(1-\frac{\lambda}{\alpha}\right) \cdot u\left(\frac{R\left(1-y^{*}\right)}{1-\lambda}\right)$ & $u\left(\frac{R\left(1-y^{*}\right)}{1-\lambda}\right)$ \\
\hline
\end{tabular}

As before, the rigidity of the contract prevents runs from happening. We still have that $c_{1}^{*}<c_{2}^{*} \equiv \frac{R\left(1-y^{*}\right)}{1-\lambda}$ and, again, rolling over is dominant if the depositor is patient. The new proposition becomes as follows.

Proposition 5.3 (Central Bank Equilibria: No Run under Equal Treatment) Assume the central bank does not punish depositors who contribute to the run, but treats them as if they had rolled over their deposit. Then, the withdrawal game of central bank depositors has a unique equilibrium. All patient depositors roll over and only impatient depositors withdraw. Runs do not occur. The socially optimal contract is always attained when offered.

\subsection{Deposit monopoly}

Given that depositors anticipate outcomes before depositing with the commercial or the central bank, we obtain our next result:

Proposition 5.4 (Central Bank Deposit Monopoly) If the central bank offers the socially optimal contract, then independently of whether it punishes depositors for contributing to a run or not, it will attract all deposits in the market away from the commercial banking sector. 
The intuition for the result is: even if the commercial banking sector offers the socially optimal contract to compete with the central bank, the commercial bank cannot prevent the bad bank run equilibrium from occurring. Thus, the commercial bank cannot guarantee the allocation under the optimal contract while the central bank can.

However, since depositors internalize that the central bank contract is run-proof, the central bank enjoys a kind of market power. If the central bank decides to exploit such market power, it can offer a different deposit contract from the socially optimal one, and still obtain a monopoly of all deposits. ${ }^{13}$ When the central bank behaves in such a way (perhaps due to political economy forces), the economy will not achieve the first-best amount of maturity transformation. The resilience of central banks to runs is a double-edged sword: it avoids financial panics, but it destroys the competitive forces that discipline central banks that are "open to all."

\section{Robustness}

Our benchmark model can be extended in many different directions to better reflect the possible advantages and disadvantages of a CBDC. In the interest of space, we focus on the robustness of our primary results to fundamental runs due to asset risk and the presence of central bank regulation.

\subsection{Fundamental runs due to asset risk}

Our benchmark model has considered a long-term, illiquid asset that exhibits no aggregate risk. The long asset pays return $R$ for sure in $t=2$. We have shown that in this case, there exist equilibrium runs on the commercial bank due to panics, but no runs on the central bank.

We now relax the assumption of a risk-free, high-return asset. For instance, we want to consider bank loans that are subject to the risk that the borrower (the long-term project in the context of our model) fails to repay for some exogenous reason (credit risk). If information reaches markets that a borrower may not repay, i.e., that the bank has issued a bad loan, a run on the bank may occur that is not driven by panic, but by information (Chari and Jagannathan, 1988, and Goldstein and Pauzner, 2005, hereafter GP).

\footnotetext{
${ }^{13}$ To see this, let $U_{1}$ the expected utility from the socially optimal but run-prone commercial bank deposit contract and $U_{2}$ the expected utility from the socially optimal but run-proof central bank deposit contract. If runs occur at the commercial bank with a strict positive likelihood along the equilibrium path (the relevant case for our argument), it holds that $U_{1}<U_{2}$. Thus, the central can find a $c_{1}<c^{*}{ }_{1}$ such that $U_{1}<$ $U\left(c_{1}\right)<U_{2}$. In words, a lower $c_{1}$ maintains the run-proofness, while lowering the utility of the depositor and generating positive profits for the central bank.
} 
To model information-driven runs, assume that the asset return $R$ is only paid with likelihood $p(\theta)$ and otherwise zero where $\theta \sim U[0,1]$ is the random state of the economy and $p(\cdot)$ is a strictly increasing, differentiable function of the state with $p(0)=0$. Assume further that bank depositors observe noisy, private and correlated signals about the return likelihood before making their decision $\theta_{i}=\theta+\varepsilon_{i}, \varepsilon_{i} \sim U[-\varepsilon, \varepsilon]$ where the noise terms $\varepsilon_{i}$ are i.i.d. and independent of the state distribution.

The payoffs at the commercial bank then become:

\begin{tabular}{l||c|c} 
Event/Action & withdraw & roll-over \\
\hline no run & $u\left(c_{1}^{*}\right)$ & $p(\theta) u\left(\frac{R\left[\left(1-y^{*}\right)-(\alpha-\lambda) c_{1}^{*} / \kappa\right]}{1-\alpha}\right)$ \\
\hline run & $\frac{\left(1-y^{*}\right) \kappa}{(\alpha-\lambda) c_{1}^{*}} \cdot u\left(c_{1}^{*}\right)$ & 0 \\
\hline
\end{tabular}

In a global games environment, GP show that a run on the commercial bank continues to exist under these circumstances. Further, it is straightforward to see that under aggregate risk, the central bank will also be subject to runs. Consider the case of equal treatment under aggregate risk:

\begin{tabular}{l||c|c} 
Event/Action & withdraw & roll-over \\
\hline no run, $\alpha=\lambda$ & $u\left(c_{1}^{*}\right)$ & $p(\theta) u\left(\frac{R\left(1-y^{*}\right)}{1-\lambda}\right)$ \\
\hline $\operatorname{run}, \alpha>\lambda$ & $\frac{\lambda}{\alpha} \cdot u\left(c_{1}^{*}\right)+\left(1-\frac{\lambda}{\alpha}\right) \cdot p(\theta) u\left(\frac{R\left(1-y^{*}\right)}{1-\lambda}\right)$ & $p(\theta) u\left(\frac{R\left(1-y^{*}\right)}{1-\lambda}\right)$ \\
\hline
\end{tabular}

Then, for sufficiently low state realizations, i.e., $\theta \in[0, \underline{\theta}]$, with $\underline{\theta}$ such that:

$$
u\left(c_{1}^{*}\right)=p(\underline{\theta}) u\left(\frac{R\left(1-y^{*}\right)}{1-\lambda}\right),
$$

withdrawing is a dominant action. In that case, a fundamental run on the central bank occurs. Unlike the case for the commercial bank described in GP, the game structure for the central bank here is not a coordination game. In equilibrium, all impatient depositors withdraw, and, thus, $\alpha$ cannot be realized below $\lambda$. Therefore, every patient depositor is pivotal: If she withdraws, she triggers a run on the central bank. But since the investment in the long asset is protected from liquidation by the rigidity of the contract, for every $\theta>\underline{\theta}$, it is dominant to roll over the deposit.

The lower dominance region for commercial bank runs is determined by the same threshold $\underline{\theta}$ given by condition (9). However, due to miscoordination, the range of state realizations for which commercial bank runs occur is larger. There exists a critical state $\theta_{b} \in(\underline{\theta}, 1]$ such that commercial bank runs occur for all states in $\left[0, \theta_{b}\right)$. 
Consequently, there exists an interval of state realizations $\left(\underline{\theta}, \theta_{b}\right)$ for which runs occur on the commercial bank, but not on the central bank under equal treatment. Depositors internalize that the central bank is safer ex-ante, and solely deposit with the central bank (giving the central bank, as before, monopoly power that can exploit to deviate from the socially optimal deposit contract).

We characterize bank runs in the next proposition under the assumption that the central bank offers the socially optimal deposit contract, a natural benchmark for our investigation, and which generates a deposit monopoly.

Proposition 6.1 (Deposit Monopoly under Asset Risk and Equal Treatment) If the central bank offers the socially optimal deposit contract, under asset risk and equal treatment, central bank runs occur for state realizations in $[0, \underline{\theta}]$, but do not arise for states $[\underline{\theta}, 1]$. Exante, runs on the central bank occur less often than runs on commercial banks and, therefore, the central bank attracts all deposits.

In the case of a run on the central bank, however, we do not get the optimal allocation if, for instance, the asset fails to pay or if an impatient depositor is forced to wait until the long asset matures. Also, as we mentioned above, while the proposition is driven by the rigidity of the contract, the main result resembles a setting where a commercial bank invests in the risky asset directly and a regulator has the authority to stop runs to protect asset liquidation once a critical measure of depositors have withdrawn. For further details on this mechanism, see Schilling (2018).

Now let us return to the case where the central bank punishes depositors who contribute to the run under asset risk. The payoff matrix now becomes:

\begin{tabular}{l||c|c} 
Event/ Action & withdraw & roll-over \\
\hline no run, $\alpha=\lambda$ & $u\left(c_{1}^{*}\right)$ & $p(\theta) u\left(\frac{R\left(1-y^{*}\right)}{1-\lambda}\right)$ \\
\hline run, $\alpha>\lambda$ & $\frac{\lambda}{\alpha} \cdot u\left(c_{1}^{*}\right)+\left(1-\frac{\lambda}{\alpha}\right) \cdot 0$ & $p(\theta) u\left(\frac{R\left(1-y^{*}\right)}{1-\alpha}\right)$ \\
\hline
\end{tabular}

Consider the state $\underline{\theta}$ defined by condition (9). First, we can verify that for all $[\underline{\theta}, 1]$, it is dominant to roll over. This is because, in equilibrium, all impatient types withdraw $\alpha \geq \lambda$. Therefore, we get again:

$$
\frac{\lambda}{\alpha} u\left(c_{1}^{*}\right) \leq u\left(c_{1}^{*}\right) \leq p(\theta) u\left(\frac{R\left(1-y^{*}\right)}{1-\lambda}\right) \leq p(\theta) u\left(\frac{R\left(1-y^{*}\right)}{1-\alpha}\right)
$$

Now consider the range $[0, \underline{\theta})$. Under equal treatment, it is dominant for consumers to withdraw for state realizations in $[0, \underline{\theta})$. Under punishment, however, this is not true. To see 
this, assume the state is realized in $\theta \in(0, \underline{\theta})$. Then, $p(\theta)>0$. Because the pro rata share $u\left(\frac{R\left(1-y^{*}\right)}{1-\alpha}\right)$ goes to infinity for $\alpha \rightarrow 1$ and because $\frac{\lambda}{\alpha} \cdot u\left(c_{1}^{*}\right) \in\left[\lambda u\left(c_{1}^{*}\right), u\left(c_{1}^{*}\right)\right]$ is bounded, there exists a measure of withdrawals $\alpha(\theta)>\lambda$ such that:

$$
\frac{\lambda}{\alpha} u\left(c_{1}^{*}\right)<p(\theta) u\left(\frac{R\left(1-y^{*}\right)}{1-\alpha}\right)
$$

for all $\alpha>\alpha(\theta)$. That is, for every low state realization $(0, \underline{\theta})$, rolling over is optimal if withdrawals are sufficiently high.

We can formalize this argument in the next proposition, again under the assumption that the central bank offers the socially optimal deposit contract.

Proposition 6.2 (Deposit Monopoly under Asset Risk and Punishment) If the central bank offers the socially optimal deposit contract, under asset risk, a central bank that punishes depositors for contributing to runs is at least as stable as the central bank that applies equal treatment. Therefore, under asset risk, the central bank is always more stable than the commercial banking sector and attracts all deposits away from the commercial banks.

The intuition for this result is simple. The punishment of depositors who contribute to a run implies a reward for depositors who roll over. Moreover, the rigidity of the contract protects depositors who roll over from receiving nothing. ${ }^{14}$ Hence, as soon as sufficiently many other depositors withdraw, the reward for rolling over is large enough to compensate for a bad outlook of the asset. The rigidity of the contract paired with the punishment-reward scheme self-regulates withdrawals and deters runs.

The deterrence of runs is always optimal and efficient if the long asset is free of risk. Under aggregate risk, however, early asset liquidation is efficient if the assets' continuation value $p(\theta) R$ falls short of the liquidation value $\kappa$, (Allen and Gale, 1998). In this situation, the rigidity of the central bank contract can cause harm and inefficient investment during a recession.

\subsection{Central bank regulation}

Our analysis has focused on the setting where the central bank can invest in both the storage technology and a loan to the investment bank. Since the central bank cannot call the loan, we have a rigidity that ultimately leads to the central bank being more stable than the commercial banking sector.

\footnotetext{
${ }^{14}$ The likelihood that the state is realized at $\theta=0$ has zero probability. Thus, the asset always pays with some probability.
} 
In principle, however, nothing prevents the central bank from investing in a demanddeposit contract with a commercial bank to conduct maturity transformation. Unlike the rigid contract with the investment bank, the commercial bank serves deposit withdrawals in the interim period on demand. As depositors start withdrawing from the central bank, the central bank withdraws from the commercial bank to finance those demands from its deposits. Since the commercial bank may liquidate the entire long asset in the interim period, depositors who roll over at the central bank may receive a zero payment. As depositors internalize this feature, central bank runs become more likely ex-ante in comparison to the case where the central bank abstains from investing in the commercial bank and only uses the investment bank. Moreover, a run on the central bank may trigger a run on the corresponding commercial bank and vice versa. Our analysis suggests the usefulness of prohibiting the central bank from investing in maturity-transforming institutions. In that way, we can prevent a bank run cascade (contagion). For related ideas, check Dasgupta (2004).

Recall, also, that the central bank can only offer the socially optimal contract when having access to the long, high-return asset, even if indirectly through the investment bank. However, as we have shown, investment in the long asset exposes the central bank to runs if the long asset is risky. If, by regulation, the central bank only invests in the short asset (i.e., highly liquid assets), central bank runs do not occur, but the socially optimal contract is only offered by the commercial banking sector. As we found before, central banks face a trade-off between offering the socially optimal contract and being run-proof.

\section{Conclusions}

In this paper, we have investigated the implications of an account-based central bank digital currency (CBDC), focusing on its potential competition with the traditional maturitytransforming role of commercial banks, as in Diamond and Dybvig (1983). The central bank cannot invest in long-term projects itself, but instead has to rely on the expert knowledge of investment banks to do so. We have derived an equivalence result that shows that the set of allocations achieved with private financial intermediation will also be achieved with a CBDC, provided competition with commercial banks is allowed and if depositors do not panic.

Nevertheless, our equivalence result has a sinister counterpart. If the competition from commercial banks is impaired (for example, through some fiscal subsidization of central bank deposits), the central bank has to be careful in its choices to avoid creating havoc with maturity transformation. Furthermore, we have shown that the rigidity of the central bank's contract with investment banks deters runs. In equilibrium, depositors internalize this feature and exclusively deposit with the central bank such that the central bank arises as a deposit 
monopolist, attracting deposits away from the commercial banking sector. But this monopoly power eliminates the forces that induce the central bank from delivering the socially optimal amount of maturity transformation.

In closing, recall that the analysis in this paper has been entirely real: all contracts are denominated in real quantities. We pursue the implications of a CBDC in a nominal setting and its inter-relations with more traditional monetary policy in Fernández-Villaverde et al. (2020). 


\section{References}

Adrian, T. And T. Mancini-Griffoli (2019): "The rise of digital money," FinTech Notes 19/001, International Monetary Fund.

Agur, I., A. Ari, And G. Dell'Ariccia (2019): "Designing central bank digital currencies," Working Paper 19/252, International Monetary Fund.

Allen, F. And D. Gale (1998): "Optimal financial crises," Journal of Finance, 53, 12451284.

(2009): Understanding Financial Crises, Clarendon Lectures in Finance, Oxford University Press.

Barontini, C. And H. Holden (2019): "Proceeding with caution - a survey on central bank digital currency," BIS Papers 101, Bank for International Settlements.

Barrdear, J. And M. Kumhof (2016): "The macroeconomics of central bank issued digital currencies," Bank of England Working Paper 605, Bank of England.

Bartels, B., B. Eichengreen, And B. Weder (2016): "No smoking gun: Private shareholders, governance rules and central bank financial behavior," CEPR Discussion Papers 11625, C.E.P.R. Discussion Papers.

Beniak, P. (2019): "Central bank digital currency and monetary policy: a literature review," MPRA Paper 96663, University Library of Munich, Germany.

Berentsen, A. And F. Schar (2018): "The case for central bank electronic money and the non-case for central nank cryptocurrencies," Federal Reserve Bank of St. Louis Review, 100, 97-106.

Bordo, M. D. And A. T. Levin (2017): "Central bank digital currency and the future of monetary policy," Working Paper 23711, National Bureau of Economic Research.

Böser, F. And H. Gersbach (2019): "A central bank digital currency in our monetary system?" Mimeo, Center of Economic Research at ETH Zurich.

Brunnermeier, M. K., H. James, And J.-P. LAndau (2019): "The digitalization of money," Working Paper 26300, National Bureau of Economic Research.

Brunnermeier, M. K. And D. Niepelt (2019): "On the equivalence of private and public money," Journal of Monetary Economics, 106, 27-41. 
Chari, V. V. And R. Jagannathan (1988): "Banking panics, information, and rational expectations equilibrium," Journal of Finance, 43, 749-761.

Cowen, D. J. (2000): The Origins and Economic Impact of the First Bank of the United States, 1791-1797, Garland Publishing.

Danezis, G. And S. Meiklejohn (2015): "Centrally banked cryptocurrencies," CoRR, abs/1505.06895.

Dasgupta, A. (2004): "Financial contagion through capital connections: A model of the origin and spread of bank panics," Journal of the European Economic Association, 2, 10491084 .

Diamond, D. W. And P. H. Dybvig (1983): "Bank runs, deposit insurance, and liquidity," Journal of Political Economy, 91, 401-419.

Diamond, D. W. And R. G. Rajan (2001): "Liquidity risk, liquidity creation, and financial fragility: A theory of banking," Journal of Political Economy, 109, 287-327.

Dyson, B. And G. Hodgson (2016): "Digital cash: Why central banks should start issuing electronic money," Tech. rep., Positive Money.

Ennis, H. M. And T. KeIster (2009): "Bank runs and institutions: The perils of intervention," American Economic Review, 99, 1588-1607.

Fernández-Villaverde, J., D. Sanches, L. Schilling, and H. Uhlig (2020): "Central bank digital currency in a nominal model of banking," Tech. rep., CREST, Polytechnique.

Friedman, M. AND A. J. Schwartz (1986): "Has government any role in money?" Journal of Monetary Economics, 17, 37-62.

Goldstein, I. And A. Pauzner (2005): "Demand-deposit contracts and the probability of bank runs," Journal of Finance, 60, 1293-1327.

Keister, T. And D. R. SAnches (2019): "Should central banks issue digital currency?" Working Paper 19-26, Federal Reserve Bank of Philadelphia.

Ketterer, J. A. And G. Andrade (2016): "Digital central bank money and the unbundling of the banking function," Discussion Paper IDB-DP-449, Inter-America Developement Bank. 
Knodell, J. E. (2017): The Second Bank of the United States: "Central" Banker in an Era of Nation Building, 1816-1836, Routledge.

Kynaston, D. (2017): Till Time's Last Sand: A History of the Bank of England, 1694-2013, Bloomsbury Publishing.

Mancini-Griffoli, T., M. S. M. Peria, I. Agur, A. Ari, J. Kiff, A. Popescu, And C. Rochon (2018): "Casting light on central bank digital currencies," IMF Staff Discussion Notes 18/08, International Monetary Fund.

Martín-AceñA, P. (2017): "The Banco de España, 1782-2017. The history of a central bank," Tech. Rep. 73, Banco de España.

_ (2018): "Money in Spain. New historical statistics. 1830-1998," Working Paper 1806, Banco de España.

Narayanan, A., J. Bonneau, E. Felten, A. Miller, and S. Goldfeder (2016): Bitcoin and Cryptocurrency Technologies, Princeton University Press.

Remini, R. V. (2017): Andrew Jackson and the Bank War, W. W. Norton \& Company.

Rogoff, K. S. (2014): "Costs and benefits to phasing out paper currency," Working Paper 20126, National Bureau of Economic Research.

Schilling, L. (2018): "Optimal forbearance of bank resolution," Becker Friedman Institute for Research in Economics Working Paper.

Tobin, J. (1987): "The case for preserving regulatory distinctions," Proceedings - Economic Policy Symposium - Jackson Hole, 167-205.

von zur Gathen, J. (2015): CryptoSchool, Springer.

Wadsworth, A. (2018): "The pros and cons of issuing a central bank digital currency," Reserve Bank of New Zealand Bulletin, 81, 1-21.

Wallace, N. (1988): "Another attempt to explain an illiquid banking system: the Diamond and Dybvig model with sequential service taken seriously," Federal Reserve Bank of Minneapolis Quarterly Review, 3-16. 


\section{Appendix}

\section{A The Commercial Bank Deposit Contract}

In this appendix, we derive the banking solution to the liquidity insurance problem, provided there are only commercial banks and depositors behave according to their type. The optimal contract will take the form of a standard demand deposit contract (i.e., a depositor can choose to withdraw from the bank either in period 1 or 2). Bertrand competition among the banks forces them to maximize the expected utility of consumers subject to feasibility conditions.

Formally, the private banking arrangement solves:

$$
\max _{\left(y, c_{1}, c_{2}\right) \in \mathbb{R}_{+}^{3}} \lambda u\left(c_{1}\right)+(1-\lambda) u\left(c_{2}\right)
$$

subject to

$$
\begin{gathered}
0 \leq y \leq 1 \\
\lambda c_{1} \leq y
\end{gathered}
$$

and

$$
(1-\lambda) c_{2} \leq R(1-y)+y-\lambda c_{1} .
$$

where $y$ is the fraction of deposits invested in the short-term technology and the remainder $1-y$ is invested in the long-term technology.

With this contract, it is optimal for all patient consumers to withdraw only in period 2, provided all other patient consumers do so, i.e., $\alpha=\lambda$ is an equilibrium. This withdrawal behavior is also the first-best solution to the social planning problem where the planner knows the type of each agent.

Because of the properties of the utility function, the banking allocation when patient consumers withdraw only in period 2 is given by:

$$
\begin{gathered}
c_{1}^{*}=\frac{y^{*}}{\lambda}, \\
c_{2}^{*}=\frac{R\left(1-y^{*}\right)}{1-\lambda}, \\
u^{\prime}\left(\frac{y^{*}}{\lambda}\right)=R u^{\prime}\left(\frac{R\left(1-y^{*}\right)}{1-\lambda}\right) .
\end{gathered}
$$

This allocation coincides with the efficient allocation derived in the planner's problem. Thus, 
the private banking arrangement provides an efficient way to insure against the idiosyncratic liquidity risk in the economy (i.e., the event of being an early consumer).

It is well known in the literature that, since types are unobservable and unverifiable and consumers have access to the storage technology, the previously described banking arrangement also features a bank run equilibrium, where $\alpha=1$. If we assume that the bank is required to liquidate all of its assets to satisfy the demand of depositors, and if all depositors withdraw, then, for $c_{1}^{*}>1$, the bank cannot serve all depositors. Since depositors know the potential of a liquidity squeeze ex-ante, a self-fulfilling run can occur in equilibrium with late consumers withdrawing early and storing the good because they believe others will withdraw early. Ennis and Keister (2009) refer to an economy that admits a bank run equilibrium such as this one as an economy with a fragile banking system.

Obviously, the bank run equilibrium is suboptimal compared to the first-best solution. It is interesting to consider second-best planning problems for comparison, but this is not the purpose of this paper. 